\title{
A note on the configuration of the digital ecossstem in Latin America
}

\section{La configuración del ecosistema digital en América Latina}

\section{Zoltán J. Ács}

Schar School of Policy and Government, George Mason University 3351 Fairfax Dr., Arlington VA 22201, USA.

zacs@gmu.edu

\section{Esteban Lafuente}

Department of Management, Universitat Politècnica de Catalunya (UPC Barcelona Tech). Av. Doctor Marañón 44-50, 08028 Barcelona, España. esteban.lafuente@upc.edu • https://orcid.org/0000-0001-5889-7656

László Szerb

University of Pécs. Pécs, Rákóczi 80, H-7622, Hungary.

szerb.laszlo@ktk.pte.hu

- Article received:

13 May, 2021

- Article accepted:

21 September, 2021

- Published online in articles in advance:

26 October, 2021

DOI:

https://doi.org/10.18845/te.v16i1.5926

* Corresponding Author

Esteban Lafuente
Abstract: We evaluate the main characteristics of the digital ecosystem of North American (USA and Canada) and 16 Latin American economies for 2019. By employing the 'benefit of the doubt' model rooted in non-parametric techniques to scrutinize a composite indicator designed to assess the digital ecosystem (i.e., the Digital Platform Economy (DPE) index), the analysis allows the computation of endogenous (country-specific) weights that can be used for developing more informed policy making. The results show that countries prioritize different aspects of their digital ecosystem which confirms that, contrary to homogeneous prescription, tailor-made policy is a more desirable approach if the objective is to optimize the resources deployed to enhance the countries' digital ecosystem.

Keywords: Digital ecosystem, digital platforms, digital infrastructures, policy, Latin America, benefit of the doubt, data envelopment analysis.

Resumen: Este estudio evalúa las principales características del ecosistema digital en América del Norte (EE.UU. y Canadá) y en 16 economías Latinoamericanas para 2019. Al aplicar el modelo del 'beneficio de la duda' originado en técnicas no paramétricas, el análisis propuesto del indicador diseñado para valorar el ecosistema digital (esto es, Digital Platform Ecosystem, DPE) permite el cálculo de pesos endógenos (específicos para cada país) que se pueden utilizar para desarrollar políticas más informadas. Los resultados muestran que los países priorizan diferentes aspectos de su ecosistema digital, lo que confirma que, contrariamente a la prescripción homogénea, el diseño de políticas específicas ajustadas al entorno local es un enfoque más deseable si el objetivo es optimizar los recursos desplegados para mejorar el ecosistema digital.

Palabras clave: Ecosistema digital, plataformas digitales, infraestructuras digitales, América Latina, beneficio de la duda, análisis envolvente de datos. 


\section{Introduction}

Today we live in an information age driven by different technologies that materialize in the application of big data, algorithms, cloud computing, and social networks. This new environmentwhich primarily results from the information technology revolution-is creating a global digital platform economy built around multiple market players, including digital platforms, entrepreneurs, and individual users who simultaneously interact with governments interested in regulating the new digital markets (Goldfarb and Tucker, 2019; Acs et al., 2021).

The interconnections between economic agents-i.e., entrepreneurs and individual users, platforms and governments-in the digital economy bring important challenges to digital platformsinterested in capitalizing on their internal architecture by connecting users and businesses-and to policy makers who are now faced with the responsibility of designing digital infrastructures and regulations that increase the efficiency of digital markets.

These market and regulatory issues have been largely addressed in the US and European economies (see, e.g., Rochet and Tirole, 2006; Sussan and Acs, 2017; Goldfarb and Tucker, 2019; Song, 2019). Nevertheless, and despite in the last decade Latin American countries have shown important progress in terms of various digitization metrics (e.g., broadband infrastructure, Internet adoption and social media coverage) (Katz and Callorda, 2018), important questions related to the digital ecosystem remain unanswered. Specifically, what are the characteristics (and drivers) of the digital ecosystem in Latin America? Moreover, are there relevant differences in the configuration of the Latin American digital ecosystem when compared to that in other developed economies (i.e., USA and Canada)?

To address these questions empirically, the objective of this note is to evaluate the digital ecosystem in Latin America and in developed American economies (USA and Canada). The empirical application employs the 'Benefit of the Doubt' (BOD) weighting method (Cherchye et al., 2007) on a unique data set including information on the properties of the digital ecosystem-measured by the Digital Ecosystem Index (DEI) (Sussan and Acs, 2017) -in North America (USA and Canada) and 16 Latin American countries for the year 2019.

For their capacity to compile into a single metric complex constructs that cannot be fully captured with one variable, composite indicators-such as the one proposed in our note based on the BOD model-have gained increased popularity among scholars and policy makers (Cherchye et al., 2007). Composite indicators constitute valuable tools for policy makers interested in identifying benchmarks as well as setting policy priorities (OECD, 2008). Studies based on composite indicators computed via the BOD method have been used in different fields including, among others, economics (e.g., internal market index, global competitiveness index or county competitiveness), human development (e.g., human development index), quality of life (e.g., better life index), or business competitiveness (Despotis, 2005; Cherchye et al., 2008; Mizobuchi, 2014; Alonso-Ubieta and Leiva, 2019; Araya-Solano, 2019; Lafuente, Araya, Leiva, 2020).

Our model is in line with prior work emphasizing the layered structure that characterizes the relationships between ecosystem participants (Parker et al., 2017; Cennamo, 2019; Li et al., 2019): governments, digital platforms, new and incumbent firms, and individual users. 
The main findings of the study reveal significant discrepancies in the efficiency level of the digital ecosystem in Latin America and North American economies. Also, it was found that the performance gap in digital ecosystem performance is in large part explained by differences in the configuration of the ecosystem between North America and developing Latin American countries.

The results of our study have important implications for scholars and policy observers interested in digital ecosystems. Economically meaningful policy to improve the digital ecosystem should be based on accurate analyses. From the perspective of the digital ecosystem, the proposed analysis contributes to understand the factors shaping the digital ecosystem in North America and Latin America. Also, our analysis provides nuanced guidance on how to support high-tech entrepreneurship by developing tailor-made policies that, at the same time, can contribute to strengthen the local digital ecosystem.

The plan of the paper follows. Section 2 presents the digital platform economy index, while Section 3 deals with the data and the description of the analytical method. Section 4 presents the results and Section 5 offers the concluding remarks, implications and future research lines.

\section{Measuring the digital ecossstem: The digital platform economy index}

In order to measure the magnitude of the digital platform economy (DPE), Acs et al. (2021) propose the Digital Platform Economy Index (DPE Index). The DPE integrates two inter-related literatures on ecosystems, namely, digital ecosystem and entrepreneurial ecosystem by situating at the core of the digital ecosystem framework different economic agents, including: users, entrepreneurs, digital platforms, and institutions. This way, the DPE works under the presumption that for technology to be successfully introduced both the digital ecosystem and the entrepreneurial ecosystem need to be developed simultaneously. The full description of the DPE computation method is presented in Appendix 1.

Concerning the measurement issues, the Digital Platform Economy Index (DPE) integrates 12 pillars grouped in four interconnected ecosystem constituents (Table 1): (1) Digital User Citizenship which includes users on the demand-side and the supply-side; (2) Digital Technology Entrepreneurship that incorporate app developers and various agents that contribute to entrepreneurial innovation and value creation on platforms; (3) Digital Multi-sided Platforms that coordinate social and economic activities between users and agents; and (4) Digital Technology Infrastructure including all regulations governing all the activities of the digital technology.

The sub-indicator dealing with Digital User Citizenship emphasizes the value of users' privacy protection for a healthy and active digital ecosystem. This building block of the DPE addresses the explicit legitimization and implicit social norms that enable users to participate in the digital society in order to increase public trust and the sustainability of the digital ecosystem (Sussan and Acs, 2017, p. 64). Variables related to digital literacy, digital openness and digital rights are critical aspects of this sub-indicator (Table 1).

The second DPE sub-indicator, Digital Technology Entrepreneurship, brings forth entrepreneurial innovation and, subsequently, increases platforms' efficiency. For a sustainable DPE, economic agents engaging in entrepreneurial innovation and knowledge exchange (e.g., add 
developers) contribute to narrow the gap between supply opportunity and demand need within platforms that increase platform efficiency (Song, 2019). In this case, decisive elements of a solid digital technology entrepreneurship environment include: digital adaptation, technology absorption and technology transfer (Table 1).

The Digital Multi-sided Platforms sub-indicator highlights the key role played by digital platforms as innovation bridges of the information technology revolution (e.g., Rochet and Tirole, 2006; Gawer 2009; Evans and Schmalensee, 2016). Saadatmand, Lindgren and Shultze (2019) describe "digital platforms as an emergent organizational form characterized by technology and social processes". By governing the mutually dependent relationships between the economic agents that consolidate the platforms' value proposition (e.g., app developers and users), digital platforms operate in multiple markets that are essential to most consumers in our contemporary economy. In order to take into account the various properties of platforms' economic environment, this sub-indicator include a number of constructs, including: networking, matchmaking, and financial facilitation (Table 1).

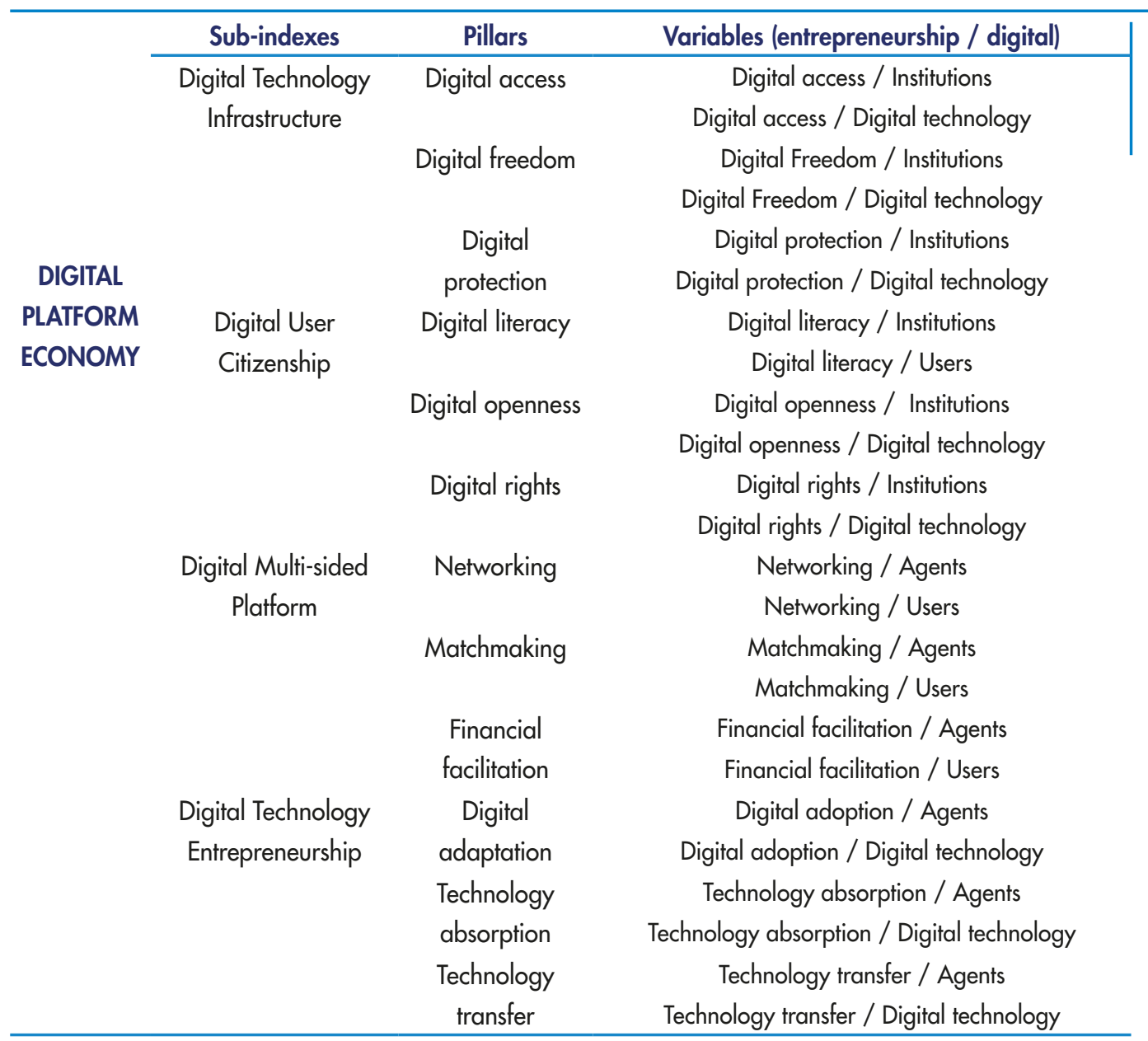

The Digital Platform Economy index (DPE) 
Finally, the Digital Technology Infrastructure sub-indicator captures the mechanisms that facilitate the functioning of the platform economy. Digital infrastructures represent the technologies of the digital age jointly with the regulations that govern their effective implementation. Appropriate technological infrastructures are essential prerequisites for the efficient operation of the digital platform ecosystem that is also responsible for ensuring an open and secure digital economy. Digital access, digital freedom, and digital protection are the components included in this sub-indicator.

\section{Design and methods}

\subsection{Sample and the digital ecosystem pillars}

The data used in this study to assess the digital ecosystem (DPE) in the American continent come from the Digital Platform Economy Index databases made available by the Global Entrepreneurship and Development Institute (www.thegedi.org) (Acs et al., 2021).

The DPE scores-and DPE constituents-were computed for a sample of 18 countries for the year 2019, including both North America and Latin America and the Caribbean islands: Argentina, Brazil, Canada, Chile, Colombia, Costa Rica, Dominican Republic, Ecuador, El Salvador, Guatemala, Honduras, Jamaica, Mexico, Panama, Paraguay, Peru, United States, and Uruguay.

\begin{tabular}{l|lcccc}
\hline Table 2: & & USA & Canada & Latin America & Total \\
\hline $\begin{array}{l}\text { BOD model (equation } \\
\text { (1)): Descriptive } \\
\text { statistics for the } \\
\text { output set (DPE sub- }\end{array}$ indicators) & Panel A: Output set & & & & \\
(DPE sub-indicators) & Digital technology infrastructure & & & & \\
& Digital user citizenship & 80.73 & 75.37 & $25.21(8.65)$ & $31.08(18.94)$ \\
& Digital multisided platforms & 79.00 & 81.34 & $26.52(10.22)$ & $32.48(19.83)$ \\
& Digital technology entrepreneurship & 87.41 & 78.83 & $23.90(8.33)$ & $30.48(20.74)$ \\
& Panel B: DPE pillars & 92.22 & 77.13 & $24.43(7.42)$ & $31.13(20.85)$ \\
& Digital openness & & & & \\
& Digital freedom & 70.44 & 74.49 & $23.28(16.25)$ & $28.75(22.06)$ \\
& Digital protection & 91.00 & 68.46 & $32.50(9.07)$ & $37.74(17.91)$ \\
& Digital literacy & 91.57 & 84.57 & $24.02(9.79)$ & $31.13(22.69)$ \\
& Digital access & 100.00 & 82.07 & $25.04(7.55)$ & $32.37(22.70)$ \\
& Digital rights & 92.33 & 85.38 & $19.08(13.78)$ & $26.83(26.04)$ \\
& Digital networking & 57.79 & 79.39 & $41.21(19.20)$ & $44.25(20.43)$ \\
& Digital matchmaking & 89.08 & 79.07 & $30.13(9.51)$ & $36.13(19.67)$ \\
& Financial facilitation & 100.00 & 76.69 & $24.99(10.50)$ & $32.03(23.09)$ \\
& Digital adoption & 90.04 & 82.57 & $19.27(8.13)$ & $26.71(23.02)$ \\
& Technology absorption & 100.00 & 79.34 & $25.65(8.38)$ & $32.76(22.43)$ \\
& Technology transfer & 100.00 & 73.66 & $27.58(9.29)$ & $34.16(21.53)$ \\
\cline { 2 - 5 } & & 100.00 & 79.71 & $22.75(8.62)$ & $30.20(23.42)$ \\
\hline
\end{tabular}

Standard deviation is presented in parentheses. The Latin America group includes 16 countries: Argentina, Brazil, Chile, Colombia, Costa Rica, Dominican Republic, Ecuador, El Salvador, Guatemala, Honduras, Jamaica, Mexico, Panama, Paraguay, Peru, and Uruguay. Source: The Global Entrepreneurship and Development Institute (www.thegedi.org). 
Concerning the output set, as we indicated in Section 2 the DPE index includes four sub-indicators that represent different constituents of the digital ecosystem: digital infrastructure governance, digital user citizenship, digital multisided platforms, and digital technology entrepreneurship. Summary statistics for the four DPE sub-indicators as well as the 12 DPE pillars are presented in Table 2. For illustrative purposes, the full data set used in this study is presented in the Appendix 2. Also, Appendix 3 includes the data for the 12 pillars included in the DPE index.

At this point, an important consideration is in order. For the purposes of this study, notice that the 12 DPE pillars were grouped into the four DPE sub-indicators (outputs) which are introduced in equation (1) to obtain the digital ecosystem performance measure ( $\left.\mathrm{DPE}^{\mathrm{BOD}}\right)\left(\mathbf{y}=y_{1}, \ldots, y_{k} \Lambda \mathrm{K}=4\right)$ : y1: digital infrastructure governance, y2: digital user citizenship, y3: digital multisided platforms, and y4: digital technology entrepreneurship. Because the sample is relatively small (i.e., 18 observations), an efficiency model with 12 outputs would produce biased results that would become evident in a large number of artificially efficient countries (Cook et al., 2014). Thus, the proposed BOD model with four outputs seeks to reduce the potential loss of discriminatory power of BOD models with large numbers of inputs and/or outputs, relative to the number of units. ${ }^{1}$

\subsection{Method: Benefit of the Doubt (BOD) weighting}

We propose that the digital ecosystem is the result of the mutual interactions between various economic agents (i.e., users, businesses, digital platforms, and public administrations) functioning in local settings with different institutional and environmental conditions. By taking this relevant property of this ecosystem into account, our analysis seeks to evaluate the digital ecosystem around the globe as well as its strengths and weaknesses with the objective to identify potentially optimal ecosystem-enhancing policies.

To construct the composite indicator, we employ the benefit-of-the-doubt (BOD) model (e.g., Cherchye et al., 2007). Rooted in non-parametric data envelopment analysis (DEA) techniques (for a survey on DEA see, e.g., Cooper et al. (2011)), the BOD weighting is among the methods suggested by the OECD (2008) for computing objective, non-arbitrary composite indicators (CIs). The BOD model, originally proposed by Melyn and Moesen (1991) and further developed by, among others, Cherchye et al. (2007), Sahoo et al. (2017) and Karagiannis and Karagiannis (2018), is a special case of the input-oriented DEA model (Charnes et al., 1978) with a single constant input (vector of 1s) (Lovell and Pastor, 1999; Karagiannis and Lovell, 2016).

Formally, for the 18 countries $(i=1, \ldots, \mathrm{N}=18)$, the BOD weighting model used in this study considers the 4 DPE sub-indicators $\left(\mathbf{y}=y_{1}, \ldots, y_{k} \Lambda \mathrm{K}=4\right)$ and employs a set of endogenous weights (w) to compute the weighted average of the seven indicators ( $y$ ) that maximize the DPE score. The following linear program solves the BOD weighting problem and computes the optimal DPE value for each county (i):

$$
D P E^{B O D}=\max \sum_{k=1}^{K} w_{i k} y_{i k} \quad k=1, \ldots, K=4 \quad i=1, \ldots, N=18
$$

1 Within the literature dealing with non-parametric frontier models, Banker et al. (1989) suggested a 'rule of thumb' to ensure the discriminatory power of DEA models: the number of observations should be at least three times the number of inputs (k) and outputs (y) ( $\mathrm{N} \geq 3 \times(\mathbf{y}+\mathbf{k}))($ Cook et al., 2014, p. 2). 
subject to:

$$
\sum_{k=1}^{K} w_{i k} y_{i k} \leq 1 ; \quad w_{i k}>0 ; \quad L_{k}<\sum_{k=1}^{K} w_{i k} y_{i k}<U_{k}
$$

Equation (1) computes for each country a vector of endogenous weights for the 4 DPE subindicators $\left(w_{k}=w_{1}, \ldots, w_{4}\right)$ that maximizes the value of the DPE. The optimal DPE performance value is bounded $\left(D P E^{B O D} \leq 1\right)$. For efficient countries on the frontier $D P E^{B O D}=1$, while for inefficient territories $D P E^{B O D}<1$ and $1-D P E^{B O D}$ is the degree of inefficiency (i.e., the output expansion required to reach the frontier). Two properties of the BOD model (equation (1)) are worth highlighting. First, weights are constrained to be non-negative, which makes the composite indicator a non-decreasing function of the output set. However, the non-negativity constraint on the weights allows for extreme scenarios that might render DPE estimations inaccurate (e.g., high number of artificially efficient countries). Thus, additional restrictions on the weights are needed in order to account for the relative importance of all DEEBOD sub-indicators. In this study, we added to equation (1) a 'pie share' restriction (Cherchye et al., 2007): $L_{k}<\sum_{k}^{K} w_{i k} y_{i k}<U_{k}$. This proportional restriction is attractive because pie shares $\left(w_{i k} y_{i k}\right)$ do not depend on measurement units and they directly show the individual contribution of each pie share to the DEEBOD, while allowing for weight heterogeneity within and between countries. In equation (1), Lk and Uk are the lower and upper bound for each pie share, respectively. The endogenous weights are country-specific and the sum of the re-scaled pie shares equals the DEEBOD score (equation (1)).

The second property deals with the relative importance-i.e., weights and limits $\left(L_{k}\right.$ and $\left.U_{k}\right)$-of the DPEBOD sub-indicators. Instead of employing homogeneous ex-post weights resulting from the optimization model in equation (1), the $\mathrm{DPE}^{\mathrm{BOD}}$ weights were generated via the data driven method described in equation (1) in which the $\mathrm{DPE}^{\mathrm{BOD}}$ score is maximized based on the configuration of the efficient benchmark countries as well as on the position of the focal country in the technology hyperplane shaped by the output set (i.e., the 4 DPE sub-indicators).

\section{Results}

\subsection{Analysis of the digital ecosystem worldwide}

This section presents the results of the evaluation of the digital ecosystem based on the measures computed via equation (1). We first analyze the results of the efficiency analysis of the digital ecosystem (DPE ${ }^{\mathrm{BOD}}$ model: equation (1)). The second part of the section deals with the analysis of the configuration of the digital ecosystem among the sampled countries.

Overall, from Table 3 we observe that the relative efficiency of the digital ecosystem is $36.43 \%$ (average $D P E^{B O D}=0.3643$ ). This finding indicates that American economies have a large room for improving their digital ecosystem. Specifically, countries in the continent can enhance the quality of their digital ecosystem $63.57 \%$ by investing-in terms of physical resources and reforms-in the different constituents of the ecosystem. Obviously, significant variations in the quality of the ecosystem are detected among the sampled countries. 
The United States is the only country reporting an efficient digital ecosystem, in terms of the BOD estimations $\left(D P E^{B O D}=1\right)$. According to our BOD model (equation (1)), Canada ranks second in our digital ecosystem composite indicator $\left(D P E^{B O D}=0.9202\right)$.

The group of Latin American countries lags behind the USA and Canada. Also, for this group we observe that only four countries report an above-average $D P E^{B O D}$ score, namely: Chile $\left(D P E^{B O D}=0.4514\right)$, Uruguay $\left(D P E^{B O D}=0.4028\right)$, Costa Rica $\left(D P E^{B O D}=0.4014\right)$, and Brazil $\left(D P E^{B O D}=0.3661\right)$. On the other hand, Honduras $\left(D P E^{B O D}=0.1595\right)$ and Guatemala $\left(D P E^{B O D}=0.1686\right)$ are the countries with the poorest digital ecosystem level $\left(D P E^{B O D}\right)$.

To analyze the configuration of the digital ecosystem among the sampled countries, we employ the weights computed via equation (1) (Table 3) to aid in the identification of the strategic patterns that characterize the digital ecosystem. The descriptive results are summarized in Table 4. Additionally, Figure 1 shows the configuration of the digital ecosystem for the benchmark (efficient) peer-i.e., the United States-and for the group of Latin American countries.

\begin{tabular}{lcccccc|}
\hline Country & Ranking & $\begin{array}{c}\text { DPEBOD } \\
\text { (eq. (1)) }\end{array}$ & \multicolumn{3}{c}{ Output weights (w) } & \\
\hline y1: Digital & $\begin{array}{c}\text { y2: Digital } \\
\text { user }\end{array}$ & $\begin{array}{c}\text { y3: Digital } \\
\text { multisided } \\
\text { technology } \\
\text { infrastructure }\end{array}$ & $\begin{array}{c}\text { y4: Digital } \\
\text { technology } \\
\text { citizenship } \\
\text { entrepreneurship }\end{array}$ \\
\hline United States & 1 & 1.0000 & 0.3100 & 0.3160 & 0.2860 & 0.2710 \\
Canada & 2 & 0.9202 & 0.3050 & 0.2830 & 0.2920 & 0.2980 \\
Chile & 3 & 0.4514 & 0.3070 & 0.2920 & 0.2730 & 0.3060 \\
Uruguay & 4 & 0.4028 & 0.3370 & 0.1940 & 0.3110 & 0.3280 \\
Costa Rica & 5 & 0.4014 & 0.3270 & 0.2790 & 0.2840 & 0.2860 \\
Brazil & 6 & 0.3661 & 0.3100 & 0.3280 & 0.2520 & 0.2940 \\
Argentina & 7 & 0.3543 & 0.2780 & 0.2670 & 0.3110 & 0.3160 \\
Mexico & 8 & 0.3426 & 0.2720 & 0.2720 & 0.3250 & 0.3050 \\
Colombia & 9 & 0.3276 & 0.2600 & 0.2980 & 0.3150 & 0.3030 \\
Panama & 10 & 0.3260 & 0.2760 & 0.2880 & 0.3440 & 0.2700 \\
Peru & 11 & 0.2760 & 0.2840 & 0.2820 & 0.3390 & 0.2730 \\
Ecuador & 12 & 0.2473 & 0.2780 & 0.2540 & 0.3310 & 0.3090 \\
Jamaica & 13 & 0.2298 & 0.3150 & 0.2770 & 0.2560 & 0.3280 \\
Dominican Republic & 14 & 0.2082 & 0.1680 & 0.3560 & 0.3230 & 0.3260 \\
El Salvador & 15 & 0.1937 & 0.3130 & 0.3010 & 0.2780 & 0.2890 \\
Paraguay & 16 & 0.1817 & 0.3020 & 0.2570 & 0.3410 & 0.2760 \\
Guatemala & 17 & 0.1686 & 0.3950 & 0.2560 & 0.2810 & 0.2530 \\
Honduras & 18 & 0.1595 & 0.3680 & 0.2660 & 0.2870 & 0.2630 \\
Total & & 0.3643 & 0.2979 & 0.2814 & 0.3040 & 0.2941 \\
\hline
\end{tabular}

BOD model: DPEBOD results (scores and 'pie shares') and ranking 
The United States, the efficient country, has a balanced digital ecosystem (Table 4 and Figure 1). The results of the BOD model ( $\mathrm{DPE}^{\mathrm{BOD}}$ in equation (1)) indicate that the digital ecosystem in this country is primarily driven by the sub-indicator related to 'user citizenship' (0.3160) and 'technology infrastructure' (0.3100). On contrary, 'technology entrepreneurship' (0.2710) and 'multi-sided platforms' (0.2860) are relatively less important factors shaping the country's ecosystem.

Although the descriptive result in Figure 1 suggests a balanced ecosystem, we observe two distinctive patterns in the configuration of the digital ecosystem of the group of Latin American countries. On the one hand, for the group of countries with an above-average DPEBOD score-i.e., Chile, Uruguay, Costa Rica-the 'technology infrastructure' sub-indicator is the most relevant aspect of their digital ecosystem whereas 'user citizenship', the top priority DPE indicator in the USA, is the weakest aspect of the ecosystem in these countries (Table 4). Because public trust is a critical prerequisite to user participation in the digital economy, this group Latin American countries should emphasize improvements in 'user citizenship' if the promotion of quality improvements in the digital ecosystem is the desired goal. For example, the development and sustainability of the digital ecosystem requires clear rules in terms of protection of personal data and enhanced privacy terms in digital platforms. Both aspects-which are included in the 'user citizenship' pillar-should be targeted by policy makers from these countries if the promotion of quality improvements in the digital ecosystem is the desired goal.

\begin{tabular}{|c|c|c|c|}
\hline \multirow{21}{*}{$\begin{array}{l}\text { Table 4: } \\
\text { Configuration of the } \\
\text { digital ecosystem: } \\
\text { Summary results }\end{array}$} & Group & $\begin{array}{l}\text { Digital ecosystem: } \\
\text { Top policy priority }\end{array}$ & $\begin{array}{l}\text { Digital ecosystem: Weakest } \\
\text { sub-indicator }\end{array}$ \\
\hline & $\begin{array}{l}\text { Panel A: Benchmark country } \\
\text { (United States) }\end{array}$ & User citizenship & Technology entrepreneurship \\
\hline & Panel B: Inefficient countries & & \\
\hline & Canada & Technology infrastructure & User citizenship \\
\hline & Chile & Technology infrastructure & Multi-sided platforms \\
\hline & Uruguay & Technology infrastructure & User citizenship \\
\hline & Costa Rica & Technology infrastructure & User citizenship \\
\hline & Brazil & User citizenship & Multi-sided platforms \\
\hline & Argentina & Technology entrepreneurship & User citizenship \\
\hline & Mexico & Multi-sided platforms & User citizenship / \\
\hline & Technology infrastructure & Multi-sided platforms & Technology infrastructure \\
\hline & Colombia & Multi-sided platforms & Technology infrastructure \\
\hline & Panama & Multi-sided platforms & Technology entrepreneurship \\
\hline & Peru & Multi-sided platforms & Technology entrepreneurship \\
\hline & Ecuador & Multi-sided platforms & User citizenship \\
\hline & Jamaica & Technology entrepreneurship & Multi-sided platforms \\
\hline & Dominican Republic & User citizenship & Technology infrastructure \\
\hline & El Salvador & Technology infrastructure & Multi-sided platforms \\
\hline & Paraguay & Multi-sided platforms & User citizenship \\
\hline & Guatemala & Technology infrastructure & Technology entrepreneurship \\
\hline & Honduras & Technology infrastructure & Technology entrepreneurship \\
\hline
\end{tabular}


On the other hand, the DPE sub-indicator related to 'multi-sided platforms' is the most important factor of the digital ecosystem among the majority of countries with a below-average DPEBOD score, namely: Ecuador, Colombia, Mexico, Panama, Paraguay, and Peru (Table 4). Despite the reported similarity in the policy priority in these countries, we observe marked differences in what concerns their least relevant DPE factor.

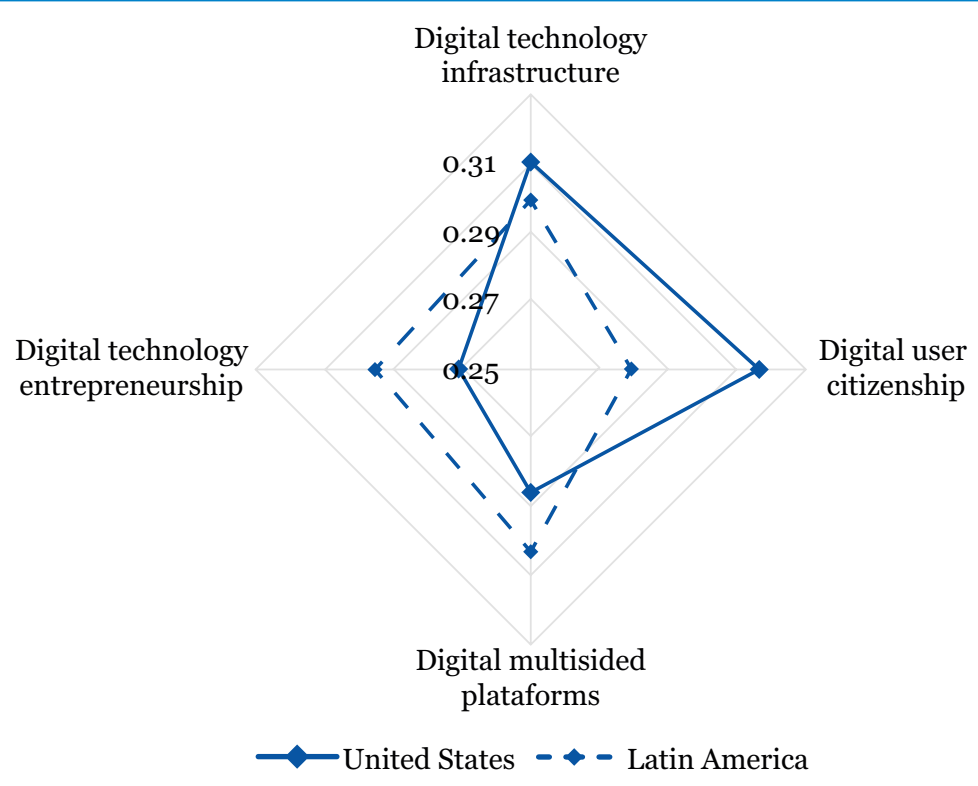

Figure 1: Configuration of the digital ecosystem: United States vs. Latin America

\subsection{The connection between the digital ecosystem and countries' economic performance}

The supplementary analysis presented in this section explores the relationship between economic performance and the quality of the digital ecosystem among the sampled countries. Specifically, we assess if the quality of the digital ecosystem, measured via the BOD efficiency scores (equation (1)), correlates with countries' economic results, measured as the GDP per capita. Notice that the GDP data was obtained from the World Bank databases and is expressed at 2011 prices in PPP international dollars. Summary descriptives for the two variables are presented in Table 5, while Figure 2 offers a visual representation of the connection between the DPEBOD score (equation (1)) and GDP per capita.

A first descriptive result indicates that there is a close connection between economic development and the digital ecosystem: Pearson correlation coefficient $=0.8732$ ( $p$-value $<0.000)$. The findings presented in Figure 2 further verify the reported strong correlation between the digital ecosystem and economic development. Notice that this result does not imply a causal relationship. We simply refer to the strong connection between economic development and the digital ecosystem among the sampled American economies. 


\begin{tabular}{|c|c|c|c|c|c|}
\hline \multirow{21}{*}{$\begin{array}{l}\text { Table 5: } \\
\text { Summary statistics: } \\
\text { The connection } \\
\text { between the digital } \\
\text { ecosystem and GDP } \\
\text { per capita }\end{array}$} & \multirow[t]{2}{*}{ Country } & \multicolumn{2}{|c|}{$\mathrm{DPE}^{\mathrm{BOD}}$ (equation (1)) } & \multicolumn{2}{|c|}{ GDP per capita (PPP in international dollars) } \\
\hline & & Mean & Ranking & Mean & Ranking \\
\hline & United States & 1.0000 & 1 & $62,794.60$ & 1 \\
\hline & Canada & 0.9202 & 2 & $48,130.30$ & 2 \\
\hline & Chile & 0.4514 & 3 & $25,222.50$ & 4 \\
\hline & Uruguay & 0.4028 & 4 & $23,572.20$ & 5 \\
\hline & Costa Rica & 0.4014 & 5 & $18,671.10$ & 8 \\
\hline & Brazil & 0.3661 & 6 & $16,096.40$ & 10 \\
\hline & Argentina & 0.3543 & 7 & $20,610.60$ & 6 \\
\hline & Mexico & 0.3426 & 8 & $19,844.60$ & 7 \\
\hline & Colombia & 0.3276 & 9 & $15,012.90$ & 11 \\
\hline & Panama & 0.3260 & 10 & $25,553.70$ & 3 \\
\hline & Peru & 0.2760 & 11 & $14,418.10$ & 12 \\
\hline & Ecuador & 0.2473 & 12 & $11,734.40$ & 14 \\
\hline & Jamaica & 0.2298 & 13 & $9,326.66$ & 15 \\
\hline & Dominican Republic & 0.2082 & 14 & $17,748.20$ & 9 \\
\hline & El Salvador & 0.1937 & 15 & $8,331.80$ & 17 \\
\hline & Paraguay & 0.1817 & 16 & $13,599.90$ & 13 \\
\hline & Guatemala & 0.1686 & 17 & $8,462.37$ & 16 \\
\hline & Honduras & 0.1595 & 18 & $5,138.75$ & 18 \\
\hline & Overall & $\begin{array}{c}0.3643 \\
(0.2343)\end{array}$ & & $\begin{array}{c}20,237.17 \\
(14,316.55)\end{array}$ & \\
\hline
\end{tabular}

Standard deviation is presented in parentheses.

Second, by observing the specific position of any given country below or above the computed trend line in Figure 2 we can offer a second descriptive analysis that is appropriate for comparison purposes. For example, the United States is the only efficient country in the American continent $\left(\mathrm{DPE}^{\mathrm{BOD}}=1.00\right)$, while Canada reports the second highest value for the digital ecosystem score $\left(\mathrm{DPE}^{\mathrm{BOD}}=0.92\right)$. But, both countries have a different position in the scatter plot presented in Figure 2. In the case of the USA, the descriptive result indicates a balanced configuration between economic development and the quality of the digital ecosystem. For Canada, the descriptive finding in Table 5 suggests that the country's digital ecosystem is potentially above the mean level expected for developed economies with a similar economic development level.

Finally, for the two countries with the poorer results (Honduras and Guatemala) the result in Figure 2 indicates that the quality of the digital ecosystem is in accordance with the economic development level of these countries. 


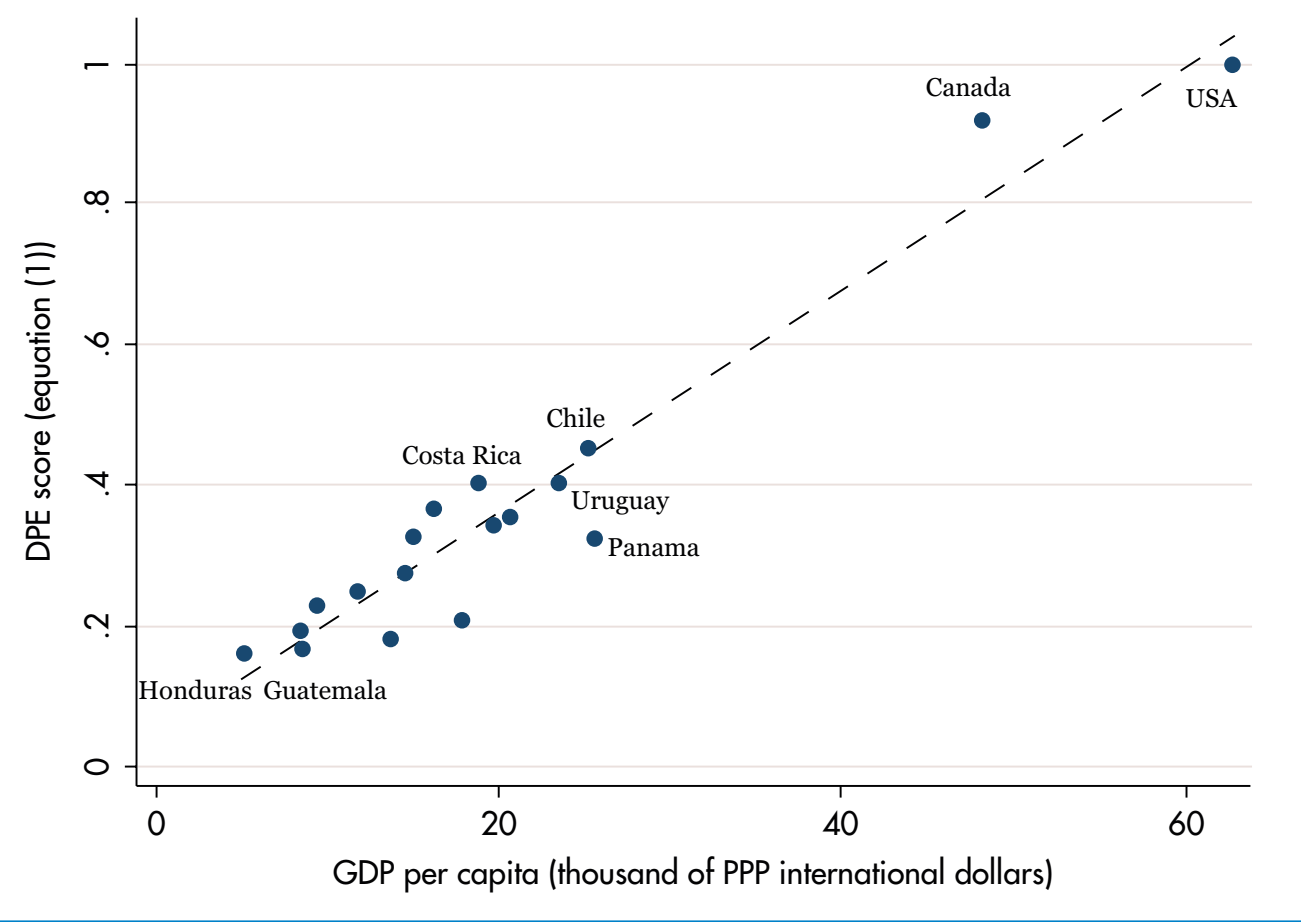

Figure 2:

Connection between the digital ecosystem (DPE $\left.{ }^{B O D}\right)$ and GDP per capita

The objective of this supplementary analysis was to show that there is a connection between economic development and the quality of the digital ecosystem, measured via the efficiency score proposed in this study (DPE ${ }^{\mathrm{BOD}}$ in equation(1)). The core finding of this descriptive exercise corroborates this intuition: the quality and configuration of the digital ecosystem can be seen as a consequence of specific policies that match the countries' economic development level.

\section{Concluding remarks}

In this study we use the data provided by the digital platform economy (DPE) index to build a non-parametric composite indicator that allows to evaluate the digital ecosystem in North and Latin America. Composite indicators have been invoked as a valuable tool, out of many available in the economists' toolkit, for analyzing complex economic phenomena, such as digital ecosystem. Despite the utter simplicity of our analysis, we are convinced that our empirical study constitutes a useful exercise.

The Latin America region is formed by highly heterogeneous countries whose domestic markets (also dissimilar in terms of size and labor conditions) need to be served. Therefore, we argue that policy analyses should go beyond canonical rankings and homogeneous recipes, and promote the exploitation of valuable information that equips policy makers with the means for implementing tailor-made policy. In this sense, accurate analyses are relevant prerequisites of effective policy design. By acknowledging the relevance of computing endogenous (country-specific) policy priorities for optimal policy, our analytical approach based on the 'benefit of the doubt' (BOD) weighting method can offer insightful information to policy makers interested in enhancing the 
local digital ecosystem. This is especially important for Latin America where most economies have deployed considerable resources and have undertaken important reforms seeking to improve the governance and functioning of their digital ecosystem (Katz and Callorda, 2018).

Overall, our results are consistent with the view that an analysis based on the BOD approach provides relevant information to identify policy priority of the digital ecosystem.

The key findings of our note reveal that in North American countries (USA and Canada) the digital ecosystem is primarily driven by aspects related to 'technology infrastructure' (e.g., digital access and digital protection) and 'digital user citizenship' (e.g., digital openness and digital rights). On contrary, we found that the most important aspects of the digital ecosystem in Latin America are related to 'digital technology entrepreneurship' (e.g., digital adaptation and technology absorption) and 'digital platforms' (e.g., networking and financial facilitation). This strategic pattern is especially evident for Latin American countries with a relatively healthy digital ecosystem: Argentina, Brazil, Chile, Costa Rica, and Uruguay.

Instead of basic rankings and homogeneous prescriptions, our analysis shows that the key policy priorities of the digital ecosystem identified by our model can eventually be targeted by policy makers if directed investments seeking to boost the digital ecosystem is the desired objective. Future work should evaluate the potential impact of a directed policy focused on the priorities identified by our model viz.-à-viz. alternative policies offered by other analytical methods.

As with any study, the findings presented in this study are open to future verification. In this sense, it would be valuable to extend the analysis in various directions. First, future work should evaluate whether a solid digital ecosystem is correlated with innovation developments at different levels (business and public administrations), and what is the role of the various constituents of the digital ecosystem in these innovation processes. Second, the proposed analysis would gain richness if future studies analyze the relationship between the digital ecosystem and alternative macroeconomic figures that, besides the GDP per capita, include other equally relevant elements of the economy (e.g., industry productivity, or changes in the digitalization of public procedures in the post Covid-19 pandemic period). Supported by our descriptive results, the scrutiny of the digital ecosystem is a relevant aspect that should enter the agenda of scholars and policy-makers; and future work should test the value of the proposed BOD model by evaluating the effectiveness of specific policies designed to target weak spots in the ecosystem identified by our model.

\section{References}

Acs, Z.J., Autio, E., Szerb, L. (2014). National Systems of Entrepreneurship: Measurement issues and policy implications. Research Policy, 43(3), 476-494.

Acs, Z.J., Szerb, L., Song, A., Komlosi, E., Lafuente, E. (2021). The Digital Platform Economy Index: 2020. Available at the Global Entrepreneurship and Development Institute (www.thegedi.org)

Alonso-Ubieta, S., Leiva, J.C. (2019). Business competitiveness in Costa Rica: A multidimensional approach. TEC Empresarial, 13(3), 28-41.

Araya-Solano, M. (2019). Efficiency assessment of Costa Rica's counties: A non-parametric analysis of the county competitiveness index. TEC Empresarial, 13(3), 78-92. 
Banker, R.D., Charnes, A., Cooper, W.W., Swarts, J., Thomas, D. (1989). An introduction to data envelopment analysis with some of its models and their uses. Research in Government and Nonprofit Accounting, 5, 125-163.

Cennamo, C. (2019). Competing in digital markets: A platform-based perspective. Academy of Management Perspectives, in press, doi: https://doi.org/10.5465/amp.2016.0048

Charnes, A., Cooper, W.W., Rhodes, E. (1978). Measuring the efficiency of decision making units. European Journal of Operational Research, 2(6), 429-444.

Cherchye, L., Moesen, W., Rogge, N., Van Puyenbroeck, T. (2007). An introduction to 'benefit of the doubt'composite indicators. Social Indicators Research, 82 (1), 111-145.

Cherchye, L., Moesen, W., Rogge, N., Van Puyenbroeck, T., Saisana, M., Saltelli, A., Liska, R., Tarantola, S. (2008). Creating composite indicators with DEA and robustness analysis: the case of the Technology Achievement Index. Journal of the Operational Research Society, 59(2), 239-251.

Cook, W.D., Tone, K., Zhu, J. (2014). Data envelopment analysis: Prior to choosing a model. Omega, 44, 1-4.

Cooper, W.W., Seiford, L.M., Zhu, J. (2011). Handbook on data envelopment analysis (2nd edition). Springer, New York.

Despotis, D.K. (2005). A reassessment of the human development index via Data Envelopment Analysis. Journal of the Operational Research Society, 56(8), 969-980.

Evans, D.S., Schmalensee, R. (2016). Matchmakers: The new economics of multi-sided platforms. Boston, Massachusetts: Harvard Business Review Press.

Gawer, A. (Ed.). (2009). Platforms, Markets, and Innovation. Cheltenham, UK ; Northampton, MA: Edward Elgar.

Goldfarb, A., Tucker, C. (2019). Digital economics. Journal of Economic Literature, 57(1), 3-43.

Karagiannis, R., Karagiannis, G. (2018). Intra-and inter-group composite indicators using the BoD model. Socio-Economic Planning Sciences, 61, 44-51.

Karagiannis, G., Lovell, C.A.K. (2016). Productivity measurement in radial DEA models with a single constant input. European Journal of Operational Research, 251 (1), 323-328.

Katz, R., Callorda, F. (2018). Accelerating the development of Latin American digital ecosystem and implications for broadband policy. Telecommunications Policy, 42(9), 661-681.

Lafuente, E., Araya, M., Leiva, J.C. (2020). Assessment of local competitiveness: A composite indicator analysis of Costa Rican counties using the 'Benefit of the Doubt' model. Socio-Economic Planning Sciences, in press, doi: https://doi.org/10.1016/j.seps.2020.100864

Li, J., Chen, L., Yi, J., Mao, J., Liao, J. (2019). Ecosystem-specific advantages in international digital commerce. Journal of International Business Studies, 50(9), 1448-1463.

Lovell, C.A.K., Pastor, J.T. (1999). Radial DEA models without inputs or without outputs. European Journal of Operational Research, 188 (1), 46-51.

Melyn, W., Moesen, W. (1991). Towards a synthetic indicator of macroeconomic performance: unequal weighting when limited information is available. Public Economic Research Paper 17, CES, KU Leuven. 
Mizobuchi, H. (2014). Measuring world better life frontier: A composite indicator for OECD better life index. Social Indicators Research, 118, 987-1007.

OECD (2008). Handbook on constructing composite indicators: methodology and user guide. OECD Publications, Paris.

Parker, G., Alstyne, M.V., Jiang, X. (2017). Platform Ecosystems: How Developers Invert the Firm. MIS Quarterly, 41(1), 255-266.

Rochet, J.-C., Tirole, J. (2006). Two-sided markets: A progress report. The RAND Journal of Economics, 37(3), 645-667.

Saadatmand, F., Lindgren, R., Schultze, U. (2019). Configurations of platform organizations: Implications for complementor engagement. Research Policy, 48(8), 103770.

Sahoo, B.K., Singh, R., Mishra, B., Sankaran, K. (2017). Research productivity in management schools of India during 1968-2015: A directional benefit-of-doubt model analysis. Omega, 66, 118-139.

Song, A.K. (2019). The Digital Entrepreneurial Ecosystem-A critique and reconfiguration. Small Business Economics, 53(3), 569-590.

Sussan, F., Acs, Z. J. (2017). The digital entrepreneurial ecosystem. Small Business Economics, 49(1), 55-73.

\section{APPENDXI}

Appendix 1. The digital platform economy (DPE) index (Source: Acs et al., 2021)

We suggest a five-level composite indicator building following as (1) indicators (2) variables, (3) pillars, (4) sub-indices, and (5) the super-index. The super index is called the Digital Platform Economy index and its sub-indices are the four frameworks. The twelve components are called pillars. Pillars are the most important constituents of the model. Pillars are comprised from 24 variables, representing digital ecosystem (12) and entrepreneurship ecosystem (12). Variables are built from 61 indicators that are the elementary building blocks of DPE index.

Indicator selection was based on three criteria:

1) Relevance of the indicator for the phenomenon we aim to measure.

2) Specificity of the variable to the phenomenon it represents.

3) Potentially flawless and clear interpretation of the indicator.

We also aimed to have the indicator available for at least 90\% of the countries, but in five cases, we could not reach this goal. For 85 countries more than 95.1\%, for 23 countries 90.195.0\%, and for 8 countries $80.1-90.0 \%$ of the indicators are available. The results for these eight countries - Benin, Burundi, Hong Kong, Jamaica, Macedonia, Madagascar, Namibia, Taiwan should be viewed with precaution. Variables were calculated from normalized indicator scores. 
Following the Global Entrepreneurship Index building methodology we provide the most important steps of calculation (Acs et al., 2014).

All pillars contain two types of variables: One is representing the Digital Ecosystem (Digital technology and Users) and the other representing the Entrepreneurship Ecosystem (Institutions and Agents). The overall influence of these two types of variables is captured by multiplying the two components:

$D P E \_$pillar $_{i, j}=D E \_$variable $_{i, j}{ }^{*} E E \_$variable $_{i, j}$

where

$i=1 \ldots . . . n$, the number of countries

DPE_pillar ${ }_{i, j}$ represents the digital entrepreneurship ecosystem pillars, $j=1, \ldots \ldots .12$

DE_pillar ${ }_{\mathrm{i}, \mathrm{j}}$ represents the digital ecosystem pillars, $j=1, \ldots . .12$

EE_pillar ${ }_{i, j}$ represents the entrepreneurship ecosystem pillars, $j=1, \ldots . .12$

After the calculation of the raw pillar scores we normalized them using the distance methodology:

DPE_pillar(norm) $)_{i, j}=\frac{D P E \_p i l l a r_{i, j}}{\text { maxDPE_pillar } r_{i, j}}$

for all $j=1 \ldots 12$, the number of pillars

where DPE_pillar(norm) $)_{i, k}$ is the normalized score value for country $i$ and pillar $j$

$\max \mathrm{DPE} \_$pillar $p_{i, j}$ is the maximum value for pillar $j$

When we calculate the normalized averages of the twelve pillars for the 116 countries, it ranges from 0.153 (Matchmaking) to 0.525 (Digital rights) with 0.361 overall average value. The different averages of the normalized values of the pillars imply that reaching the same pillar values requires different efforts and resources. Consequently, the effect of additional resources to achieve the same marginal improvement of the pillar values is different and it is problematic for using the pillar values to public policy purposes. The Average pillar adjustment methodology developed by Acs, Autio and Szerb (2014) reduces but not fully eliminates this problem.

The following equations (A3a-A3c) show the calculation steps.

First, we calculate the average value of the $j=12$ pillar:

$\left.\overline{D P E \_ \text {pillar(norm) }}\right)_{j}=\frac{\left.\sum_{\mathrm{i}=1}^{\mathrm{n}} \mathrm{DPE} \_ \text {pillar(norm }\right)_{i, j}}{\mathrm{n}}$ for all $j$

where $\overline{\text { DPE_pillar(norm) }}$ is the average value of all $j=12$ normalized pillars

We transform the DPE_pillar(norm) $)_{i, j}$ values such that the potential values to be in the $[0,1]$ range.

$D P E \_$pillar $(\text {equal })_{i, j}=$ DPE_pillar(norm $)_{\mathrm{i}, \mathrm{j}}^{\mathrm{t}}$

where $t$ is the "strength of adjustment", the $t$-th moment of DPE_pillar(norm)j is exactly the needed average, $\overline{\text { DPE_pillar(norm) }}$ j 
We have to find the root of the following equation for $\mathrm{t}$ :

$$
\left.\sum_{\mathrm{i}=1}^{\mathrm{n}} \mathrm{DPE} \_ \text {pillar(norm) }\right)_{\mathrm{I}, \mathrm{j}}^{\mathrm{t}}-\mathrm{n} \overline{\left.\mathrm{DPE} \_ \text {pillar(equal }\right)_{\mathrm{j}}}=\mathrm{o}
$$

For solution, the Newton-Raphson method is used with an initial guess of o. After obtaining $\mathrm{t}$, the computations are straightforward. After these transformations, the penalty for bottleneck methodology was used to create pillar-adjusted PFB values. A bottleneck is defined as the worst performing pillar or a limiting constraint in a particular country's digital entrepreneurship system. Here, bottleneck is defined as the lowest level of a particular pillar, relative to other pillars in a particular country. This notion of a bottleneck is important for policy purposes considering the systemic nature of DPE. The system perspective means that that pillars have an effect to one another. This interaction should be included in the calculation of the pillar, the sub-index and the DPE index scores. We consider the system being optimal if all the average adjusted pillar scores are the same for the particular country. Differences imply non-optimal use of the resources. Practically it means that after equalizing the pillar averages, the value of each pillar of a country is penalized by linking it to the score of the pillar with the weakest scores in that country. This simulates the notion of a bottleneck; if the weakest pillar were improved, the whole DPE Index would show a significant improvement.

We define our penalty function following as:

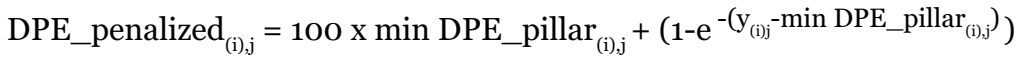

where DPE_penalized ${ }_{\mathrm{i}, \mathrm{j}}$ is the modified, post-penalty value of pillar $j$ in country $i$

DPE_pillar(equal $)_{\mathrm{i}, \mathrm{j}}$ is the normalized value of index component $j$ in country $i$

DPE_pillar(equal) min $_{\text {in }}$ is the lowest value of $y_{\mathrm{i}, \mathrm{j}}$ for country $i$.

$\mathrm{i}=1,2, \ldots \ldots .116=$ the number of countries

$\mathrm{j}=1,2, \ldots \ldots .12=$ the number of pillars

Note, that the multiplication by 100 is purely practical to get a $0-100$-point scale instead of the $0-1$ range.

Sub-index calculation is simple, just taking the arithmetic average of its PFB-adjusted pillars for that sub-index.

$$
\begin{aligned}
& D I G_{i}=\sum_{j=1}^{3} \frac{\text { DPE_penalized }_{j}}{3} \\
& D U G_{i}=\sum_{j=4}^{6} \frac{D P E \_ \text {penalized }_{j}}{3} \\
& D M S P_{i}=\sum_{j=7}^{9} \frac{D P E \_ \text {penalized }_{j}}{3} \\
& D T E_{i}=\sum_{j=10}^{12} \frac{D P E \_ \text {penalized }_{j}}{3}
\end{aligned}
$$

where

$D I G_{i}=$ Digital Technology Infrastructure score for country $i$ 
$D U C_{i}=$ Digital User Citizenship score for country i

$D M S P_{i}=$ Digital Multi-sided Platform score for country i, and

$D T E_{i}=$ Digital Technology Entrepreneurship score for country i

Finally, the Digital Platform Economy index (DPE) score is calculated as the simple arithmetic average of the four sub-indices.

$D P E_{i}=\frac{1}{4}\left(D I G_{i}+D U C_{i}+D M S P_{i}+D T E_{i}\right)$

Where $\mathrm{DPE}_{\mathrm{i}}$ is the Digital Platform Economy index score for country $i$.

\begin{tabular}{|c|c|c|c|c|c|c|}
\hline & Country & $\begin{array}{l}\text { y1: Digital } \\
\text { infrastructure } \\
\text { governance }\end{array}$ & $\begin{array}{c}\text { y2: Digital } \\
\text { user citizenship }\end{array}$ & $\begin{array}{l}\text { y3: Digital } \\
\text { multisided } \\
\text { platforms }\end{array}$ & $\begin{array}{l}\text { y4: Digital } \\
\text { technology } \\
\text { entrepreneurship }\end{array}$ & $\begin{array}{r}\text { Appendix 2: } \\
\text { Digital platform } \\
\text { economy (DPE) }\end{array}$ \\
\hline 1 & Argentina & 31.81 & 33.15 & 28.44 & 27.99 & index 2019: Count \\
\hline 2 & Brazil & 29.51 & 27.94 & 36.35 & 31.17 & Outpu \\
\hline 3 & Canada & 75.37 & 81.34 & 78.83 & 77.13 & model (equation (1)) \\
\hline 4 & Chile & 36.70 & 38.66 & 41.30 & 36.85 & \\
\hline 5 & Colombia & 31.50 & 27.47 & 26.00 & 27.05 & \\
\hline 6 & Costa Rica & 35.28 & 36.02 & 30.67 & 35.03 & \\
\hline 7 & Dominican Republic & 30.94 & 14.61 & 16.11 & 15.99 & \\
\hline 8 & Ecuador & 22.23 & 24.30 & 18.66 & 20.02 & \\
\hline 9 & El Salvador & 15.46 & 16.09 & 17.41 & 16.76 & \\
\hline 10 & Guatemala & 10.66 & 16.44 & 15.02 & 16.68 & \\
\hline 11 & Honduras & 10.84 & 15.01 & 13.92 & 15.16 & \\
\hline 12 & Jamaica & 18.24 & 20.71 & 22.40 & 17.51 & \\
\hline 13 & Mexico & 31.51 & 31.53 & 26.32 & 28.06 & \\
\hline 14 & Panama & 29.55 & 28.28 & 23.68 & 30.19 & \\
\hline 15 & Paraguay & 15.02 & 17.66 & 13.33 & 16.44 & \\
\hline 16 & Peru & 24.28 & 24.46 & 20.37 & 25.30 & \\
\hline 17 & United States & 80.73 & 79.00 & 87.41 & 92.22 & \\
\hline 18 & Uruguay & 29.84 & 51.94 & 32.36 & 30.70 & \\
\hline
\end{tabular}




\section{APPENDXIIII}

\begin{tabular}{|c|c|c|c|c|c|c|c|c|c|c|c|c|c|c|}
\hline & Country & Y1 & Y2 & Y3 & Y4 & Y5 & Y6 & Y7 & Y8 & Y9 & Y10 & Y11 & Y12 & Appendix 3: \\
\hline 1 & Argentina & 37.16 & 34.04 & 26.36 & 28.24 & 30.68 & 43.51 & 31.29 & 34.11 & 21.22 & 32.08 & 24.05 & 28.73 & ecor \\
\hline 2 & Brazil & 22.06 & 33.92 & 33.89 & 22.83 & 28.93 & 32.86 & 35.54 & 45.56 & 31.86 & 26.28 & 35.85 & 32.95 & 2019: Country data \\
\hline 3 & Canada & 74.49 & 68.46 & 84.57 & 82.07 & 85.38 & 79.39 & 79.07 & 76.69 & 82.57 & 79.34 & 73.66 & 79.71 & es) \\
\hline 4 & Chile & 35.87 & 41.18 & 34.48 & 31.11 & 27.67 & 62.76 & 53.97 & 33.44 & 40.63 & 35.58 & 40.92 & 35.49 & \\
\hline 5 & Colombia & 26.47 & 36.75 & 33.82 & 25.48 & 24.77 & 33.33 & 31.11 & 28.07 & 19.76 & 26.22 & 27.73 & 28.05 & \\
\hline 6 & Costa Rica & 38.85 & 40.56 & 33.34 & 43.36 & 15.52 & 62.04 & 40.74 & 35.66 & 20.57 & 38.58 & 48.09 & 26.21 & \\
\hline 7 & $\begin{array}{c}\text { Dominican } \\
\text { Republic }\end{array}$ & 62.80 & 30.71 & 20.29 & 17.19 & 1.52 & 29.98 & 22.78 & 11.58 & 17.84 & 14.24 & 17.89 & 19.39 & \\
\hline 8 & Ecuador & 17.26 & 27.10 & 24.29 & 26.28 & 23.37 & 25.79 & 25.15 & 20.08 & 11.91 & 25.23 & 18.11 & 17.94 & \\
\hline 9 & El Salvador & 2.94 & 30.61 & 17.35 & 14.69 & 2.87 & 36.43 & 25.17 & 18.13 & 12.82 & 15.24 & 30.61 & 8.86 & \\
\hline 10 & Guatemala & 2.63 & 19.87 & 11.26 & 18.94 & 3.64 & 31.92 & 22.33 & 15.68 & 9.96 & 17.23 & 21.96 & 14.28 & \\
\hline 11 & Honduras & 4.01 & 19.63 & 11.19 & 21.19 & 0.61 & 28.83 & 22.17 & 11.35 & 11.56 & 15.80 & 18.30 & 14.93 & \\
\hline 12 & Jamaica & 11.57 & 44.24 & 5.89 & 26.01 & 15.44 & 25.13 & 35.04 & 16.52 & 21.66 & 27.72 & 23.76 & 5.06 & \\
\hline 13 & Mexico & 27.09 & 33.54 & 36.83 & 28.88 & 35.51 & 33.02 & 28.23 & 33.47 & 18.74 & 25.49 & 31.98 & 28.20 & \\
\hline 14 & Panama & 22.58 & 47.33 & 23.59 & 27.62 & 18.58 & 42.49 & 35.97 & 20.85 & 16.17 & 29.68 & 36.34 & 28.00 & \\
\hline 15 & Paraguay & 12.17 & 18.68 & 14.77 & 13.68 & 9.57 & 32.19 & 14.45 & 15.44 & 10.39 & 14.86 & 13.96 & 21.40 & \\
\hline 16 & Peru & 12.92 & 39.69 & 24.13 & 21.21 & 16.64 & 39.07 & 21.82 & 21.96 & 18.24 & 26.25 & 24.97 & 27.21 & \\
\hline 17 & United States & 70.44 & 91.00 & 91.57 & 100.00 & 92.33 & 57.79 & 89.08 & 100.00 & 90.04 & 100.00 & 100.00 & 100.00 & \\
\hline 18 & Uruguay & 36.15 & 22.08 & 32.79 & 33.93 & 49.91 & 100.00 & 36.39 & 37.97 & 24.92 & 39.88 & 26.71 & 27.23 & \\
\hline
\end{tabular}

Note: $Y 1=$ Digital openness, $Y 2=$ Digital freedom, $Y 3=$ Digital protection, $Y 4=$ Digital literacy, $Y 5=$ Digital access, $Y 6=$ Digital rights, $Y 7=D i g i t a l$ networking, $Y 8=$ Digital matchmaking, Y9= Financial facilitation, $Y 10=$ Digital adoption, $Y 11=$ Technology absorption, $Y 12=$ Technology transfer. 